\title{
OPTIMIZATION OF THE GLOBAL OBJECTIVES OF THE SYSTEM
}

\author{
Karimov Zhasur Hasanovich \\ Assistant, \\ Ferghana Polytechnic Institute, \\ Uzbekistan, \\ Ferghana
}

\author{
Fozilov Ibrohim Rakhimovich \\ Senior Lecturer, \\ Ferghana Polytechnic Institute, \\ Uzbekistan, \\ Ferghana
}

\author{
Egamberiyev Xomidjon Abdullayevich \\ Assistant, \\ Ferghana Polytechnic Institute, \\ Uzbekistan, \\ Ferghana
}

Article DOI: https://doi.org/10.36713/epra4558

\begin{abstract}
Issues of optimizing the technological modes of operation of multi-stage processes are considered. It is noted that decomposition and the creation of local control subsystems according to the stages of processes is one of the possible ways to solve the global optimization problem. The sequence of optimization procedures is determined that allow to achieve such controlled values at each stage technological parameters at which the state of the process will be capable of completing production tasks.
\end{abstract}

KEYWORDS: Multi-stage processes, optimization, decomposition, control loop, optimization procedure.

\section{INTRODUCTION}

The optimization of technological modes of operation of multi-stage systems is an important part of modern control theory. Research and development of effective methods for its implementation is of great importance for economic, organizational and other tasks. The main mathematical apparatus for solving the optimization problem is mathematical programming.

Optimization of multi-stage processes requires solving complex linear or non-linear programming problems with mathematical models of a special structure. A modern multi-stage system with continuous and continuously-discrete technology is a multidimensional branched complex and consists of several relatively independent industries, in each of which the raw materials go through the sequential stages of processing in technological processes carried out in single or parallel plants [1-2].

Taking into account the specifics of the optimization process allows, instead of solving the global problem, to move to a series of significantly smaller local subtasks and corresponding coordination of their goals. Obviously, the decomposition and the creation of local control subsystems according to the stages of the processes is one of the possible ways to solve this problem.

\section{MATERIAL AND METHODS}

The meaning of decomposition in this case is to use the a priori information about the structure of the object to simplify the task of synthesizing the model. However, the task of identifying and synthesizing a control system for multi-stage processes (CS MSPs), which especially works in structure and in the mode of complex 
use of multicomponent raw materials, remains far from solved today. Here typical difficulties arise associated with the optimization of a hierarchical multilevel structure, each subsystem of which has not only specific parameters, local simplified models and limitations, but also its own optimization criteria. Moreover, in many cases, the optimality of the operation of subsystems and local control systems (CS) or is in an implicit and complex relationship with the optimal control of multi-stage processes (MSPs) in general.

Consider the approach of multi-level decomposition of the structure of multi-stage processes (MSPs), based on the specific features of MSPs and optimization problems. At the same time, significant relationships remain between the models of production and its individual parts.

A multi-stage system consists of a global control subsystem defined by a vector objective function.

$$
Y(x)=\left\{f_{k}(x), x \geq 0, k=\overline{1, k}\right\}
$$

where - $x=\left\{x_{j}, j=\overline{1, N}, x_{j} \geq 0\right\}$ vector of unknowns $\mathrm{i} \mathrm{k}-$ the number of downstream local control subsystems $f_{k}(x), k=\overline{1, K}$, which can be both directly controlled and regulated by the process, as well as the controlling subsystem for subordinate subsystems, where $\mathrm{K}$ - is the set of indices of local subsystems.

Let $X=\left\{x_{j}, j=\overline{1, N}\right\}$ - be a vector of unknowns expressing performance indicators, for example: volume, cost, quality, costs, etc. $j$ - th type of products manufactured by the entire system, where $N$ - many indices of types of products where $\mathrm{k}$ is the set of product indices; $X_{k} \in x, k=\overline{1, K}$ - vector of unknowns expressing product performance, produced by $k \in K$ local subsystem produced, $X_{k}=\left\{x_{j}, j=\overline{1, N_{k}}\right\}$, where $N_{k}$ - is the set of indices of types of products, released by $k \in K$ local subsystem, $N_{k} \in N$.

The main goal of the global control subsystem is to optimize all the criteria of the local subsystems,

$$
\operatorname{extr} Y(x)=\left\{f_{k}(x), x \geq 0, l=\overline{1, K}\right\} \text {, }
$$

which are equally important and equivalent for the upper control subsystem, i.e. preference is not given to any local subsystem. In this case, it is necessary to find such a vector $X^{0}$ and accordingly $X_{k}^{0} \in X^{0}$, in which all local subsystems would reach their optimum under the conditions of fulfilling resource limits

$$
R(x) \leq C, \quad r_{i}(x) \leq c_{i}, x \geq 0, i=\overline{1, M},
$$

where $i$ - is the type of resources, which are required upon release, $M$ - many indices of types of resources; $c_{i}$-restrictions on the $i$ - th type of resources.

As a rule, in MSPs, each k-th local subsystem has its own objective functions

$$
f_{k}(x), x \geq 0, k=\overline{1, K} \text {, }
$$

and limitations

$$
R^{k}\left(x_{k}\right) \leq C^{k}, r_{i}^{k}\left(x_{k}\right) \leq c_{i}^{k}, x_{k} \geq 0, i \in M, k=\overline{1, K} .
$$

The goal of each local MSP subsystem is to extremize its criterion, which may be profit, quality, management cost, production costs, etc. Here it should be emphasized that the criteria of local MSP subsystems do not necessarily correspond to the global system criterion, $t$.e. local and global criteria may be different, but local criteria should help achieve a global goal.

In relation to specific MSPs, in particular, Portland cement processing, in [3-5] the issues of constructing inter-circuit optimization procedures are considered. The idea of this approach is to decompose MSPs into control loops interconnected by internal material flows. In this case, the decomposition is carried out by minimizing the number of allocated control loops, with an unambiguous determination of the goal function of the entire system through intermediate input and output parameters of the control loops.

\section{DISCUSSION RESULTS}

As a result, the global optimization problem can be reduced to solving several local problems of substantially lower dimension: inter-circuit and a number of similar problems of contour optimization. This leads to a two-level optimization algorithm for MSPs based on the above-formulated procedures [6-7 ].

The top-level optimization problem is formulated as follows:

$$
\theta_{\text {omb }}\left(\alpha_{i}, \gamma_{\alpha_{i}}, \beta_{i}, \gamma_{\beta_{i}}, \theta_{i}, \gamma_{\theta_{i}}\right) \rightarrow \min
$$


subject to the conditions

$$
\begin{aligned}
& \theta_{j} \geq f_{j}\left(\alpha_{i}, \gamma_{\alpha_{i}}, \beta_{i}, \gamma_{\beta_{i}}, \theta_{i}, \gamma_{\theta_{i}}\right), \\
& \gamma_{\beta_{i}}^{-} \leq \gamma_{\beta_{i}} \leq \gamma_{\beta_{i}}^{+}, \beta_{\beta_{i}}^{-} \leq \beta_{i} \leq \beta_{i}^{+}, \\
& \beta_{n}=\beta_{3 a g}, \alpha_{i}>0, \theta>0, i, j=1,2, \ldots, n .
\end{aligned}
$$

The technological parameters of $\gamma_{\alpha_{i}}, \gamma_{\beta_{i}}$ and $\gamma_{\theta_{i}}$ are used in the formation of the objective function and the constraints of the optimization problem, therefore, when calculating the rational technological mode of operation of MSPs, it is necessary to specify the matrix of connections and $\left\|K_{i, j}\right\| \mathrm{i}\left\|X_{i, j}\right\|$..

At the upper level, on the basis of information about the raw materials arriving for processing and the accepted criterion, the problem of inter-circuit optimization in the space of parameters characterizing the internal flows connecting the control loops is solved. In this case, the control parameters of each circuit remain unchanged. Solving the problem of inter-circuit optimization, we find such values of the output parameters of each circuit for which the selected function of the goal of the entire system reaches its extremum. Thus, at the first stage, the optimal connections between the circuits are determined and, for each of them, the optimal values of the output variables that provide the extremum of the selected target control function for the entire system. The process of optimizing and making optimal decisions in the conditions of MSPs is implemented, as a rule, because of the principles of decomposition of the global original problem into a set of local sub-tasks of lower dimension and the construction of a decentralized control system. Therefore, each subsystem-control contour of MSPs is endowed with a certain degree of freedom of choice of local solutions and is characterized by a local quality indicator. The contours of multi-stage systems are elements of a system that are allocated according to a specific functional feature that meets specific management goals and objectives. In the framework of solving tasks of one functional purpose, the MSP subsystem can be considered as an independent system. If MSPs are divided into separate, sequentially interconnected material, energy and information flows circuits, then each of them corresponds to the contour shown in Fig. 1,

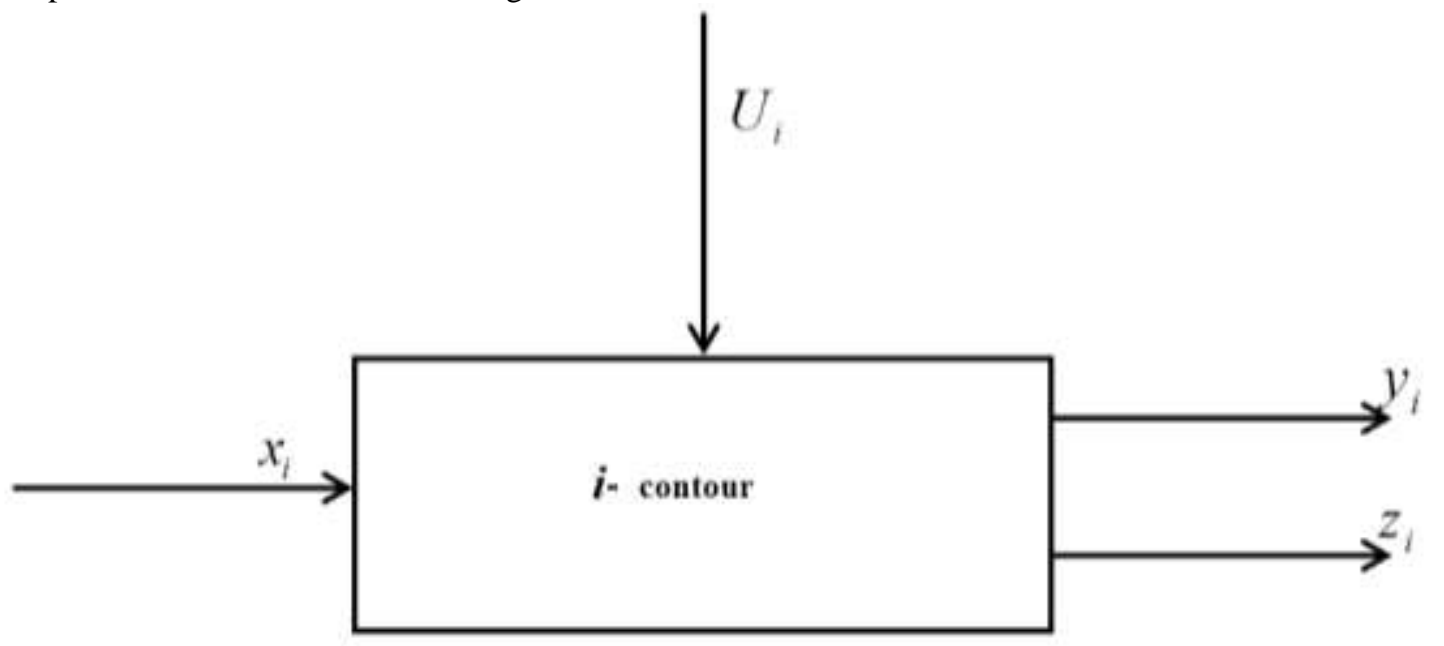

Fig. 1. Scheme of the $i$-th contour of the MSPs.

where $x_{i}$-is the vector of input parameters, containing both controlled and uncontrolled (controlled disturbing) parameters supplied to the $i$-th contour; $u_{i}$ - - vector of control parameters for the $i$-th contour; $, y_{i}, z_{i}-$ vectors of output parameters, which mean, respectively, finished production and dump products of the $i$-th contour.

If there is information about the values of the vector of input, output and control parameters, the behavior of the $i$-th contour of the MSP is determined by the mathematical model 


$$
y_{i}=f_{i}\left(x_{i}, u_{i}, z_{i}, \alpha_{i}\right)
$$

where $\alpha_{i}$-are the coefficients of the mathematical model of the $i$-th contour.

For a certain type of raw material, an appropriate model is built.

The problem of contour optimization of MSPs can be formulated as follows. It is assumed that there is a mathematical model of the form (1) for the $i$-th contour of the MSP. The selection of the contour optimization criterion is carried out according to the results of the upper level of optimization (inter-contour). At the same time, the results of inter-circuit optimization are used as specified and it is required to maintain the output indices of the control loops within the specified, lowered from the upper level of optimization. This is achieved by varying the control parameters of the contour in the allowable area with stable values of the input parameters of the contour. To solve the problem of contour optimization in the quality of the criterion - the function of the goal) a minimum of material costs for management can serve.

$$
\sum_{k=1}^{n_{i}} C_{i} U_{i k} \rightarrow \min _{u_{i} \in u}
$$

upon fulfillment of the conditions

$$
\begin{gathered}
\left|y_{i 3 a g}-f_{i}\left(x_{i j}, u_{i k}, z_{i l}\right)\right| \leq \rho \\
x_{i j} \geq 0, \quad u_{i k} \geq 0, \quad z_{i l} \geq 0
\end{gathered}
$$

and fulfillment of bilateral restrictions on intermediate and dump products (parameters) of the $i$-th contour $z_{i l}^{-} \leq z_{i l} \leq z_{i l}^{+}$, where $Y_{i 3 a g}$ - is the set value of the output indicator of the $\boldsymbol{i}$-th contour, determined as a result of solving the problem of inter- contour optimization; $C_{k}$ - the cost of the $k$-th management; $i$ - contour number: $j, k$ - numbers of input and control parameters; $z_{i l}^{-}, z_{i l}^{+}$- the number of control parameters in the $i$ th contour; $l$-intermediate product number, for example dumps, $z_{i l}^{-}, z_{i l}^{+}$- respectively, the lower and upper boundaries of the change of the $l$-th intermediate parameter of the $i$-th contour.

In addition, when solving the problem of contour optimization, it is necessary to take into account the restrictions on the control parameters arising from the features of the control loop. The circuits of the MSP are designed for a certain performance; therefore, it can be written that the vector of control parameters of the $U_{i}$ at any time $t_{\alpha}$ must belong to the set.

$$
U=\left\{U_{i} \in R^{n}: U_{i k}^{-} \leq U_{i k} \leq U_{i k}^{+}, k=\overline{1, N}\right\},
$$

where $U_{i k}^{-}, U_{i k}^{+}$are the lower and upper bounds of the change in the $k$ - th control parameter of the $i$ - th loop.

In most cases, determining the exact optimal value of the vector of control parameters satisfying condition (1), (3) is a very time-consuming procedure. Therefore, the optimal values are found by approximate methods [8]: studies of classical analysis functions based on the use of indefinite Lagrange multipliers; calculus of variations; dynamic, linear, nonlinear programming, maximum principle. All these methods have varying degrees of accuracy and computational complexity. The formulated problem of contour optimization in the conditions of MSPs is solved taking into account the topology of the schemes (structure) of the system and the characteristics of the feedstock. For each type of raw material, a scheme (routes) for processing raw materials is determined, control loops are allocated, an appropriate model is built for each loop, and the problem of loop optimization is solved taking into account the sequence of arrangement of loops in space and time delays.

Summarizing the material costs spent on managing each circuit of MSPs, we define the total cost spent on ensuring the effective functioning of MSPs as a whole.

$$
\sum_{i=1}^{m} \sum_{k=1}^{n_{1}} C_{k} U_{i k}=U
$$

where $U-$ is the total cost of managing MSPs in general.

In most cases, one-time optimization of all parameters that determine the course and results of the process in multi-parameter MSPs is not possible. In this regard, first of all, it is necessary to determine the sequence of procedures for optimizing the work, allowing at each stage to achieve such values of controlled 
technological parameters at which the state of the process will be able to fulfill production tasks.

Thus, the implementation of the contour optimization algorithm determines the implementation of the following steps [1-4]:

- recognition of the type of feedstock and materials; the choice of a set of reference models of the model of the corresponding technological situation;

- checking the model for adequacy; adjustment of model parameters;

- selection of contour optimization criterion; analysis of the task of the upper level of optimization;

- determination of the permissible restriction area for the parameters of the control loop;

- coordination of the criteria for contour and inter- contour optimization; determination of the optimal values of the control parameters of the control loop, providing an extremum for the selected function of the target;

- analysis of the results of contour optimization and decision making.

The search for optimal solutions is a difficult task, which is even more complicated by the side factors that complicate its formulation and solution.

\section{CONCLUSION}

In order to build an optimal system for automated control of the circuits of MSPs, it is necessary to synthesize the optimal control, which can be implemented as a rational technological mode, using the information on the control circuit and the optimality criterion. However, the optimal mode synthesized based on the available a priori information about the control loop will not remain optimal for long. During the operation of the technological control loop, its parameters change (aging, wear, changes in the characteristics of raw materials, etc.) and the established mode ceases to be optimal. In this regard, it becomes necessary to determine new parameters of the control object in order to restore the optimal mode of operation of the technological process.

Such a system as a whole is an optimal automatic control system with adaptation.

\section{ACKNOWLEDGMENTS}

The authors are grateful to the chief scientific associate of the Fergana Polytechnic Institute PhD, Head of the Department of Informatics and Information Technology A.A.Kuchkarov

\section{REFERENCES}

1. Kirillov A.N. Upravleniya mnogostadiynymi tekhnologicheskimi protsessami. Vestnyk SPbGU. Cep. 10, 2006, Byp.4.S.127-131

2. Dorofeyeva L.I. Modelirovaniye i optimizatsiya razdelitel'nykh protsessov. Tomsk: Izd-vo Tomskogo politekhnicheskogo universiteta, 2008. - $128 \mathrm{~s}$.

3. Vergun A.P., Savostina N.V. Optimizatsiya razdelitel'nykh protsessov. - Tomsk, 2002. - $36 \mathrm{~s}$.

4. Lugovskoy V.I. Sinyavskiy K.S. Dubs R.V. Matematicheskoye modelirovaniye khimiko-tekhnologicheskikh protsessov. - Odessa: OPU, 2004. - 35 s.

5. Alishev SH. A. Ortik, ov Z.U. Adaptivnyye modeli prognozirovaniya kachestva tsementa.zhurn. Informatsionnyye tekhnologii modelirovaniya i upravleniya. M.: Izdatel'stvo «Nauchnaya kniga», 2018, $111 \mathrm{~s}$.

6. Taymasov B. T. Tekhnologiya proizvodstva portlandtsementa. Ucheb. Posobiye.-Shymkent. Izd-vo YUKGU, 2003.-297s.

7. Kusimov S.T., Il'yasov B.G., Ismagilova L.A., Valeyeva R.G. Intellektual'noye upravleniye proizvodstvennymi sistemami. M.: Mashinostroyeniye $2001 \mathrm{~g}-327 \mathrm{~s}$.

8. Karimov ZH.KH., Fozilov I.R. Upravleniye mnogostadiynymi protsessami putom optimizatsii global'nykh tseley sistemy // Universum: Tekhnicheskiye nauki : elektron. nauchn. zhurn. 2020. № 3(72). URL: http://7universum.com/ru/tech/archive/item/9157 